\title{
Power hardware in the loop validation of fault ride through of VSC HVDC connected offshore wind power plants
}

\author{
Ranjan SHARMA, Qiuwei WU ( $\bowtie)$, \\ Seung Tae CHA, Kim H. JENSEN, \\ Tonny W. RASMUSSEN, Jacob ØSTEGAARD
}

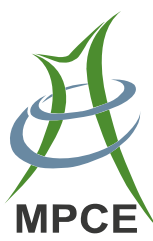

\begin{abstract}
This paper presents the power hardware in the loop (PHIL) validation of a feed forward DC voltage control scheme for the fault ride through (FRT) of voltage source converter (VSC) high voltage DC (HVDC) connected offshore wind power plants (WPPs). In the proposed FRT scheme, the WPP collector network AC voltage is actively controlled by considering both the DC voltage error and the AC current from the WPP AC collector system which ensures fast and robust FRT of the VSC HVDC connected offshore WPPs. The PHIL tests were carried out in order to verify the efficacy of the proposed feed forward DC voltage control scheme for enhancing the FRT capability of the VSC HVDC connected WPPs. The PHIL test results have demonstrated the proper control coordination between the offshore WPP and the WPP side VSC and the efficient FRT of the VSC HVDC connected WPPs.
\end{abstract}

Keywords Fault ride through, High voltage DC (HVDC), Offshore wind power plant, Power hardware in the loop (PHIL), Voltage source converter (VSC)

Received: 26 January 2014/ Accepted: 7 March 2014/ Published online: 20 March 2014

(C) The Author(s) 2014. This article is published with open access at Springerlink.com

R. SHARMA, K. H. JENSEN, Siemens Wind Power A/S, Borupvej 16, 7330 Brander, Denmark

Q. WU, S. T. CHA, T. W. RASMUSSEN, J. ØSTEGAARD, Centre for Electric Power and Energy, Department of Electrical Engineering, Technical University of Denmark, Elektrovej 325, 2800 Kongens Lyngby, Denmark

$(\bowtie)$ e-mail: qw@elektro.dtu.dk

\section{Introduction}

Voltage source converter (VSC) high voltage DC (HVDC) connection has become a new trend for long distance offshore wind power transmission. Power transmission of an offshore wind power plant (WPP) is conventionally done via high voltage AC (HVAC) submarine cables. It has been confirmed by quite a lot of research that the maximum transmission distance of a HVAC sub-marine cable transmission system is limited, especially due to surplus charging current of the cables $[1,2]$. The VSC HVDC transmission system has the ability to overcome these limitations and offers other advantages over the HVAC transmission system [3-6]. The choice between a HVAC and a HVDC transmission system depends upon many factors such as total energy losses, system cost, required system services, power control-ability, etc. It is generally more efficient to transport power over a HVDC line for high power and long distances (larger than $100 \mathrm{~km}$ ). A common technique for long distance power transmission is to utilize a mixed AC/DC system with a medium voltage AC (MVAC) collector network at the WPP and a HVDC transmission line.

One of the most challenging issues connecting an offshore WPP via a VSC HVDC transmission line to the host power system is to fulfill the grid code requirements during power system faults. It is essential to ensure that the offshore WPPs can stay connected during host system fault conditions in order to meet the fault ride through (FRT) requirements specified by various grid codes. This topic has been investigated in a number of literatures [7-14]. In [8], a controlled demagnetization method was proposed to realize fast voltage drop at the sending end converter (SEC) and fast power reduction from the WPP during a three phase fault in the host system. In [9], a control structure for 
a full converter wind turbine based WPP was presented including de-loading the fully rated converter wind turbines and emulating short circuit in the WPP collector system by reducing the voltage at the offshore HVDC converter terminal. In [12], a control strategy was developed in order to define the optimal converter valve blocking time according to the severity of the fault and alleviate the oscillations at the electrical system after deblocking the converter valves. In [13] and [14], control strategies were proposed to realize FRT of HVDC connected offshore WPPs through offshore converter control by sending out power orders to individual wind turbines or by frequency modulation in the offshore $\mathrm{AC}$ collector system. DC voltage control and power dispatch schemes of a multi-terminal HVDC system for integrating large offshore wind farms were proposed in [15] for both normal operation and onshore grid fault ride through. A new hybrid HVDC connection for large wind farms with doubly fed induction generators (DFIGs) was proposed which is comprised of a line-commutated converter plus a static synchronous compensator (STATCOM) on the rectifier side and a pulse-width modulation (PWM) current source inverter (CSI) on the inverter side, and the startup process and the system performance under both normal and fault conditions were demonstrated with such a hybrid HVDC connection connected wind farms [16].

This paper presents the development of a feed forward DC voltage control scheme in order to improve the FRT capability of a VSC HVDC connected offshore WPP. The proposed DC voltage control scheme considers both the DC voltage error between the reference and the measured value and the AC current measurements from the WPP collector system in order to achieve fast and robust FRT of the VSC HVDC connected offshore WPP. The proposed method uses active control of the collector network AC voltage level in order to realize a controlled response from the WPP, as such, the total active power generation from the wind turbines is reduced. The proposed DC voltage control scheme is verified by power-hardware-in-the-loop (PHIL) tests.

The paper is arranged as follows. The FRT technique based on the feed forward DC voltage control is presented in Sect. 2. In Sects. 4 and 5, the PHIL test setup and the test results are presented, respectively. In the end, the conclusion is drawn.

\section{Feed forward DC voltage control based FRT technique for VSC HVDC connected WPP}

The decoupling between the WPP collector grid and the in-land transmission system (host power system) makes it impossible for the wind turbines to directly respond to the voltage changes at the main grid without any external influence. In this paper, a feed forward DC voltage control based technique to control the AC voltage at the WPP collector network during grid side faults is proposed.

Under the steady state condition, the total active power generated by the WPP is determined by the wind velocity or the external power set points (for example park controller). The total active power is transmitted over the WPP collection network and the WPP side VSC converts the available AC power into DC power while maintaining its terminal voltage and angle. Individual wind turbines are set at constant reactive current mode. The reactive current is pre-calculated as per the parameters of the collector network to compensate for the reactive power. The grid side VSC delivers the DC power to the host power system while maintaining the HVDC voltage at the grid side DC capacitor. The sending-end HVDC voltage is slightly higher because of the cable resistance.

When a three phase fault occurs at the HV side of the grid transformer, the grid side VSC will respond by injecting higher active current into the system to balance the HVDC voltage and hence the active power flow. However, if the voltage dip is large enough, the current limits of the grid side VSC will restrict any further increase in active current. At the same time during a voltage dip, the reactive current control of the grid side VSC takes over the highest priority role as per the grid code requirements [17] and further reduces the active power capacity. To calculate the reference value of reactive current delivered to the grid, the measured voltage (at the LV side of the grid transformer) is compared against a reference value and a voltage gain $k_{v, \text { gain }}=2$ is applied to the difference.

$i_{k q p}^{r}(n)=k_{v, g a i n} \cdot i_{q, \lim } \cdot\left(v_{g d, r e f}-v_{g d, e q}(n)\right)$,

where $i_{q, \lim }$ is the maximum $q$ axis current limit; $v_{g d, r e f}$ is the reference grid voltage; and $v_{g d, e q(n)}$ is the equivalent grid voltage measured from the LV side of the transformer.

$v_{g d, e q(n)}=v_{d p}(n)-i_{d q}(n) \cdot X_{t x}$,

where $v_{d p}$ is the voltage magnitude at the LV side of the grid transformer; $X_{t x}$ is the transformer equivalent impedance.

As a result, the active power transfer will be reduced and limited, and the DC voltage will start to increase if the WPP is producing the same amount of active power as under the pre-fault condition. The rate of the DC voltage increase $\left(\mathrm{d} v_{d c} / \mathrm{d} t\right)$ is mainly determined by the amount of active power generated by the WPP and the equivalent capacitors at the HVDC side.

In the proposed control method, it is set that the WPP side VSC control is actively monitoring the WPP end HVDC voltage. As soon as the HVDC voltage exceeds the pre-defined threshold $\left(v_{d c, t h}\right)$, the WPP side VSC is set to take over the HVDC voltage control role. 


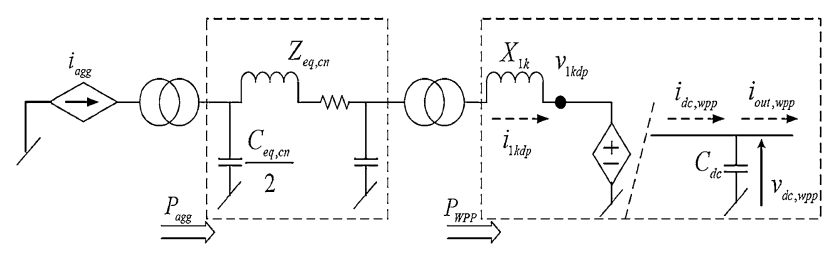

Fig. 1 Single line diagram of a WPP and the WPP side HVDC VSC

A single line layout of the electrical system at the WPP is shown in Fig. 1. Based on the fact that the wind turbines are equipped with a full-converter system, they represent a current source and their response to the change in collector network voltage is very fast.

The derivation of the applied control is presented below. During the derivation, it is assumed that the converter is lossless. Further, if it is also assumed that the voltages and the currents at the AC side are balanced, the expressions for the AC side and DC side active powers can be written as,

$$
\begin{aligned}
& P_{w p p}=\frac{3}{2} \cdot\left(v_{1 k d p}(t) \cdot i_{1 k d p}(t)+v_{1 k q p}(t) \cdot i_{1 k q p}(t)\right), \\
& P_{d c, w p p}=i_{d c, w p p}(t) \cdot v_{d c, w p p}(t) .
\end{aligned}
$$

The AC side power and the DC side power are equal if the losses in the system are neglected.

$P_{w p p}=P_{d c, w p p}$,

$v_{1 k q p}^{r}=0$, which implies,

$i_{d c}(t)=\frac{3 \cdot\left(v_{1 k d p}^{r}(t) \cdot i_{1 k d p}(t)\right)}{2 \cdot v_{d c, w p p}(t)}$.

In (6), current $i_{1 k d p}(t)$ is given by the wind farm. The collector network voltage is set by the WPP side VSC, so the AC voltage $v_{1 k d p}(t)$ is also the reference value for the converter voltage controller. Under the normal operating condition, $v_{1 k d p}^{r}(t)$ is equal to $1.0 \mathrm{pu}$. During FRT, the WPP side VSC is assigned to control the collector network AC voltage and consequently the DC voltage at the HVDC transmission side. A properly implemented DC voltage control maintains the energy balance over the DC capacitor, and any imbalance will lead to an increase in the DC voltage level given by Eq. (8).

$i_{d c, w p p}(t)-i_{\text {out }, w p p}(t)=C_{d c} \cdot \frac{\mathrm{d} v_{d c, w p p}(t)}{\mathrm{d} t}$.

Integrating the above equation over the sampling period $n \cdot T_{s}$ to $(n+1) \cdot T_{s}$, the following expression can be derived,

$$
\begin{aligned}
i_{d c, w p p}(n)-i_{\text {out }, w p p}(n)= & C_{d c} \cdot \frac{1}{T_{s}} \\
& \cdot\left(v_{d c, w p p}(n+1)-v_{d c, w p p}(n)\right),
\end{aligned}
$$

where $v_{d c}(n+1)$ is the DC voltage reference of $v_{d c}^{r}(n)$.

Substituting (7), the following expression can be derived,

$$
\begin{aligned}
v_{1 k d p}^{r}(n)= & \frac{2}{3} \cdot \frac{v_{d c, w p p}(n)}{i_{1 k d p}(n)} \cdot \frac{C_{d c}}{T_{s}} \cdot\left(v_{d c, w p p}^{r}(n)-v_{d c, w p p}(n)\right) \\
& +\frac{2}{3} \cdot \frac{v_{d c, w p p}(n)}{i_{1 k d p}(n)} \cdot i_{\text {out }, w p p}(k)
\end{aligned}
$$

The control of the WPP side VSC during a FRT event can be established based on (9). The first part in (9) consists of the system gain and the error of the DC voltage which can be further applied to a PI controller. The second part in (9) is the feed forward term. Compared to the response time of the HVDC voltage controller, the response time of the current control in wind turbines is relatively fast and, therefore, can be considered as ideal. The design of the HVDC voltage control can follow a standard procedure with the plant transfer function given as, $\left(C_{d c} \cdot T_{s}\right) /(z-1)$. When the DC voltage exceeds the threshold limit, the AC voltage at the collector network is reduced by the WPP VSC. This drop in AC voltage is seen by the wind turbines and the implemented FRT within the wind turbines will respond by reducing the active current and increasing reactive current injection. The excess of energy in the wind turbine system during different faults can either be stored in the rotating mass of the wind turbine blades or dissipated on a chopper resistor.

However, it has to be noted that the collector network consists of sub-marine cables. Cables are generally capacitive, so the sudden drop in AC voltage magnitude at the collector network will induce discharging transient current from the capacitors. A peak spike current of approximately 1.25 pu during a complete short circuit fault was observed in the simulation results for a duration of 10-15 ms. For a very large WPP, this current spike needs to be considered during VSC dimensioning.

\section{PHIL test setup}

The PHIL test is a technique where the interface point involves conservation of energy such that real power is virtually exchanged between the simulation and the actual hardware. The closed-loop PHIL of the device and the hardware provides insight of both the performance of the control scheme and its effect on the connected hardware. 


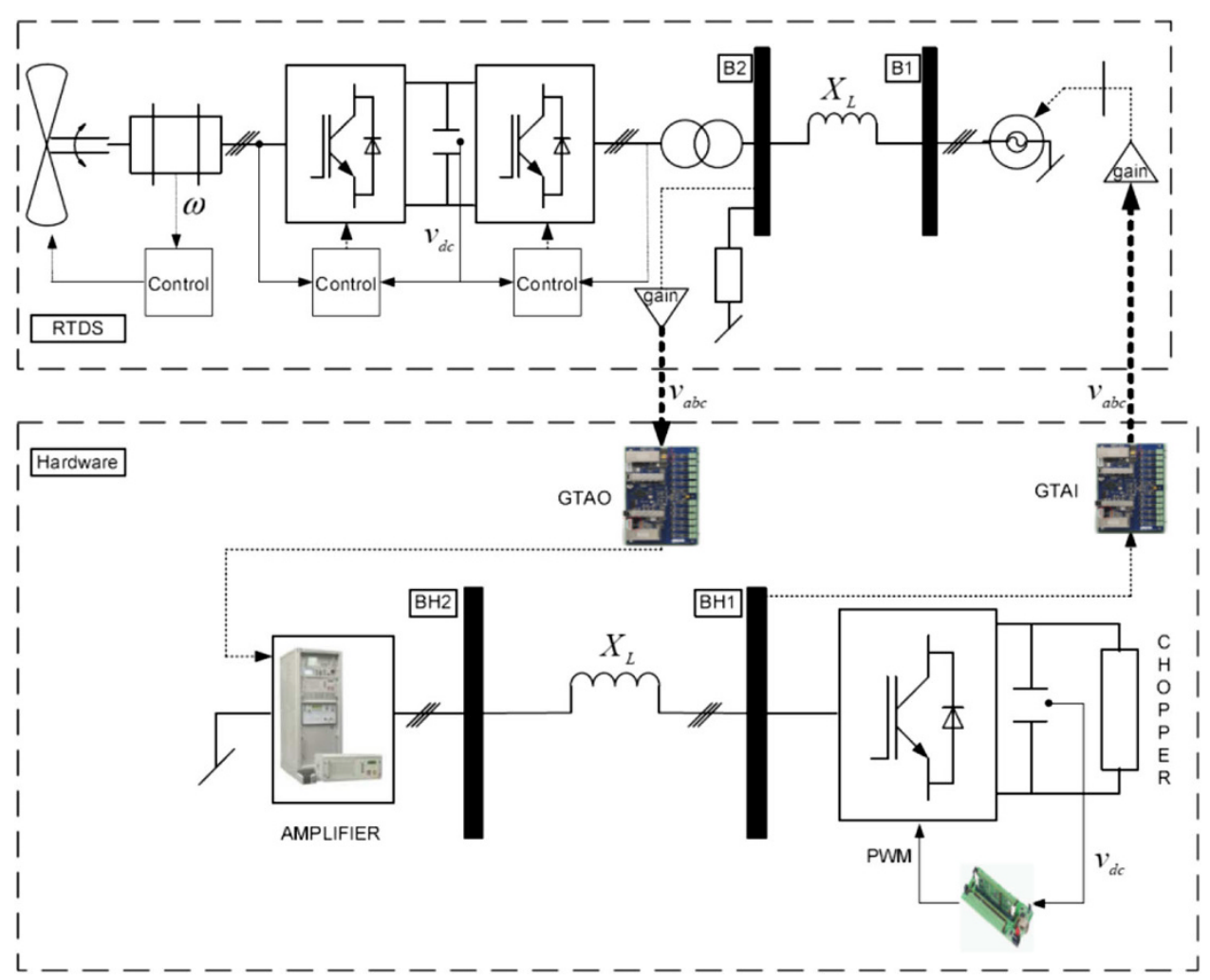

Fig. 2 Block diagram of the PHIL test

The PHIL test platform for the FRT tests of VSC HVDC connected WPPs is comprised of a RTDS (Real Time Digital Simulator), a Spitzenberger \& Spies three phase $7.5 \mathrm{~kW}$ power amplifier, a VSC and a DC chopper. The schematic diagram of the PHIL test platform is shown in Fig. 2.

The top half of Fig. 2 presents the fully rated converter PMSG based wind turbine model which is used to represent the aggregated model of the WPP, and a transformer implemented in the RTDS platform. The bottom half is the representation of the hardware component setup. The communication between the RTDS and the external hardware components is done via an analogue I/O interface. This interface system is composed of a GTAO card and a GTAI card. A proper scaling factor is implemented in the simulation to accurately amplify the voltage magnitude to and from the external channels. The HV side of the wind turbine transformer is connected via impedance to a controlled voltage source with a rated voltage at $33 \mathrm{kV}$. The control signal for the voltage source is the input from the measurements done at the output bus (BH1) of the external VSC. The external VSC represents the WPP side VSC of a HVDC line.

The DC voltage of the external VSC is terminated through a DC chopper. The role of the DC chopper is to maintain an acceptable constant DC voltage. The DC chopper emulates the role of the grid end VSC. For what is

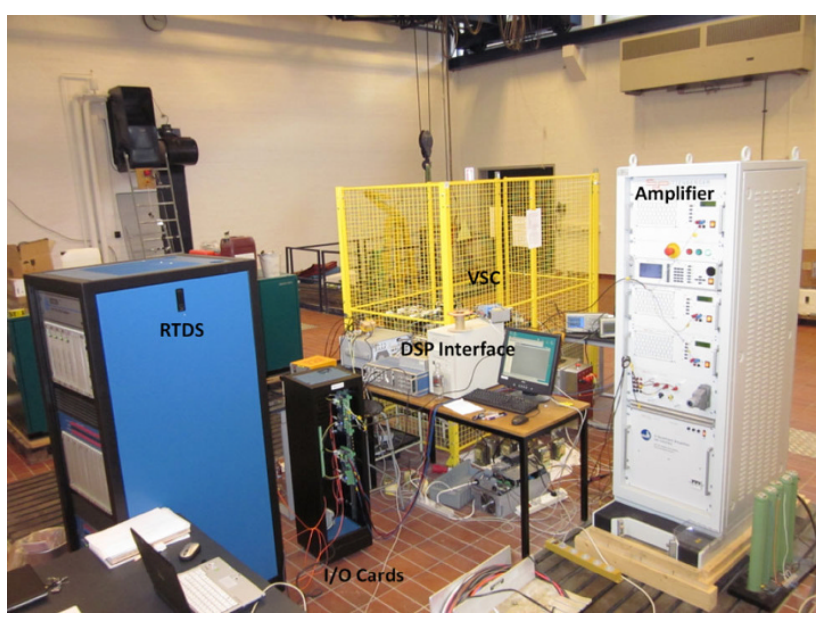

Fig. 3 The PHIL lab setup

being evaluated, the use of the chopper to emulate the grid end VSC is fully justifiable because the DC chopper can maintain the DC voltage to a given value and the other responsibilities of the grid end VSC does not affect the DC side. The PHIL test platform, shown in Fig. 3, helps investigate different control scenarios of a HVDC connected WPP during various power system operations and is also flexible for future extension. 

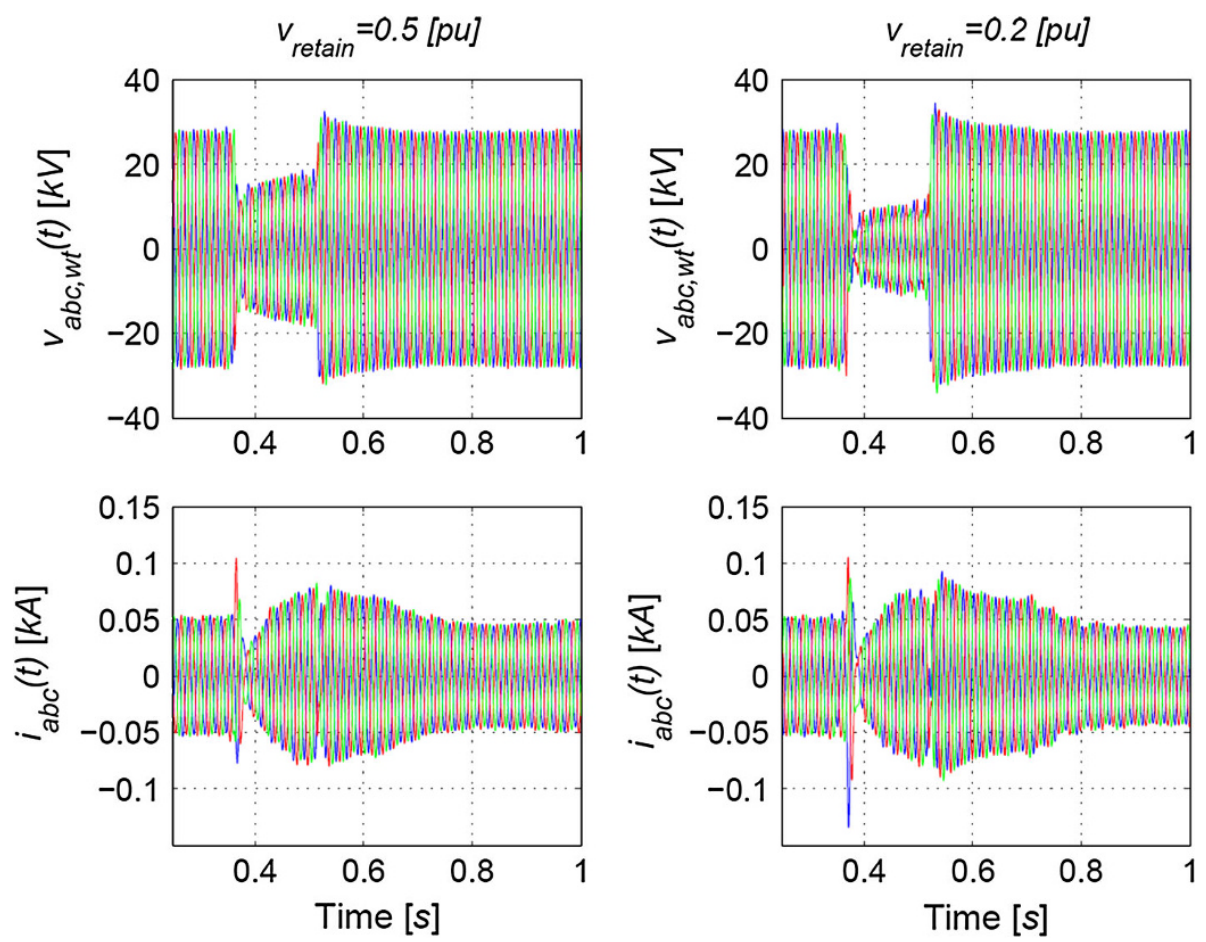

Fig. 4 Measured voltage and current at the HV of the WTG transformer during the PHIL test

\section{PHIL test results}

In order to verify the coordinated response of the offshore WPP and the WPP side VSC under AC voltage dip situations in the host power system, the control system of the WPP side VSC is triggered into FRT mode such that the VSC responds by lowering its retain voltage level. Two different voltage retain levels were evaluated at $v_{\text {retain }}=$ $0.5 \mathrm{pu}$ and $v_{\text {retain }}=0.2 \mathrm{pu}$ with $\Delta t_{\text {fault }}=150 \mathrm{~ms}$.

The voltage and current of the system at the HV side of the wind turbine transformer are shown in Fig. 4. It can be seen that the AC voltage of the WPP VSC is reduced right after the fault is detected which is reflected the HVDC voltage. After the HVDC voltage exceeds the threshold (1.1 pu), the WPP collector system voltage is reduced considering both the DC voltage difference and the current from the WPP collector system.

After the WPP collector system voltage is reduced, the wind turbine control is triggered into the FRT mode and limits the active power output while the reactive current is determined by the level of voltage dip. The limitation of the active current is given by (10).

$i_{k w d}=\sqrt{i_{\lim , w t}^{2}-i_{k w q}^{2}}$.

A peak surge current can be observed immediately after the fault is detected. Apart from the reference current limitation and control scheme, a low-level hardware protection is always implemented on a VSC to protect
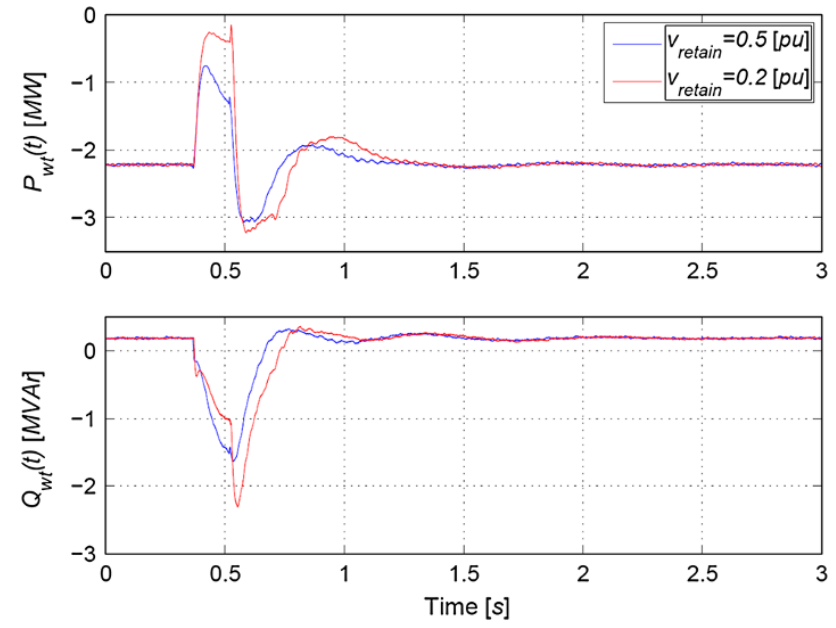

Fig. 5 Measured active and reactive power exchange from the WPP during the PHIL test

the switching devices from excessive over-current which is activated when the high level protection fails to limit the current. However, the peak surge current (half sine-wave) carrying capacity for $t_{\text {surge }}<10 \mathrm{~ms}$ of IGBTs is much higher than the nominal current capacity. Therefore, the current spike seen in the plots will not affect the wind turbine VSC or the WPP side VSC.

The active and reactive power outputs from the wind turbine are shown in Fig. 5 for the two different voltage dip levels. The convention used is such that the direction of 
active and reactive power from the wind turbine towards the collector grid is taken as negative. The difference in the active power between the generator side VSC and the grid end VSC of the wind turbine is slightly stored in the DC link capacitor and mainly dissipated in the chopper resistor. When the voltage dip is cleared, the active power from the generator end VSC plus the energy stored in the DC capacitor is suddenly released in to the collector network. What is implemented in this work is a very harsh power recovery condition for the wind turbine and collector network during the post fault period. The total active power delivered by the power amplifier measured at the hardware side at steady state prior to the applied voltage dip is $P_{w t, h w} \approx 1.8 \mathrm{~kW}$.

It is often not possible to extract every detail of a real system response from a scaled down experimental setup. Nevertheless, a scaled down system can be effectively used to test the control system validation and interaction. From the presented results, it can be summarized that an active control of AC voltage at the WPP collector network can provide a suitable FRT response as demanded by the grid codes. It is also verified from the PHIL test results that the interaction between these components are satisfactory under both normal and voltage dip situations.

\section{Conclusion}

A feed forward DC voltage control scheme has been proposed in order to enhance the FRT capability of the VSC HVDC connected WPPs under host power system faults. The proposed feed forward DC voltage control scheme considers both the DC voltage error between the reference and measured values, and the AC current from the WPP collector system ensuring fast and robust FRT. The PHIL tests show that the proposed feed forward DC voltage control scheme can fast and efficiently reduce the WPP collection system voltage when there is a voltage dip in the host power system and the wind turbines within the WPP can be triggered into the FRT model, and reduce active power and supply reactive power. As such, the proposed feed forward DC voltage can successfully enable the VSC HVDC connected WPP ride through faults in the host power systems.

Open Access This article is distributed under the terms of the Creative Commons Attribution License which permits any use, distribution, and reproduction in any medium, provided the original author(s) and the source are credited.

\section{References}

[1] Sharma R, Rasmussen TW, Jensen KH et al (2010) Modular VSC converter based HVDC power transmission from offshore wind power plant: compared to the conventional HVAC system.
In: Proceedings of the 2010 IEEE EPEC, Halifax, NS, Canada, 25-27 August 2010, p 6

[2] Negra NB, Todorovic J, Ackermann T (2006) Loss evaluation of HVAC and HVDC transmission solutions for large offshore wind farms. Electr Power Syst Res 76(11):916-927

[3] Jovcic D, Strachan N (2009) Offshore wind farm with centralised power conversion and Dc interconnection. IET Gener Transm Distrib 3(6):586-595

[4] Bresesti P, Kling W, Hendriks R et al (2007) HVDC connection of offshore wind farms to the transmission system. IEEE Trans Energy Convers 22(1):37-43

[5] Jovcic D (2006) Interconnecting offshore wind farms using multiterminal VSC-based HVDC. In: Proceedings of the 2006 IEEE power engineering society general meeting, 18-22 June 2006, p 7

[6] Ackermann T (2005) Wind power in power systems. Wiley, Chichester

[7] Xue Y, Akhmatov V (2009) Grid-connection of large offshore wind farms utilizing VSC-HVDC: modeling and grid impact. Wind Eng 33:417-432

[8] Feltes C, Wrede H, Koch F, Erlich I (2009) Enhanced fault ridethrough method for wind farms connected to the grid through VSC-based HVDC transmission. IEEE Trans Power Syst 24(3):1537-1546

[9] Ramtharan G, Arulampalam A, Ekanayake J, Hughes F, Jenkins N (2009) Fault ride through of fully rated converter wind turbines with ac and dc transmission. IET Renew Power Gener 3(4):426-438

[10] Jiang-Häfner Y, Ottersten R (2009) HVDC with voltage source converters-a desirable solution for connecting renewable energies. In: The proceedings of the 2009 large-scale integration of wind power into power system, Bremen, Germany, 14-15 October 2009, p 5

[11] Arulampalam A, Ramtharan G, Caliao N et al (2008) Simulated onshore-fault ride through of offshore wind farms connected through VSC HVDC. Wind Eng 32:103-113

[12] Vrionis T, Koutiva X, Vovos N et al (2007) Control of an HVDC link connecting a wind farm to the grid for fault ridethrough enhancement. IEEE Trans Power Syst 22(4): 2039-2047

[13] Xu L, Yao L, Sasse C (2007) Grid integration of large DFIGbased wind farms using VSC transmission. IEEE Trans Power Syst 22(3):976-984

[14] Xu L, Andersen BR (2006) Grid connection of large offshore wind farms using HVDC. Wind Energy 9:371-382

[15] Xu L, Yao L (2010) DC voltage control and power dispatch of a multi-terminal HVDC system for integrating large offshore wind farms. IET Renew Power Gener 5(3):223-233

[16] Zhou H, Yang G, Wang J et al (2011) Control of a hybrid highvoltage DC connection for large doubly fed induction generatorbased wind farms. IET Renew Power Gener 5(1):36-47

[17] Shafiu A, Anaya-Lara O, Bathurst G et al (2006) Aggregated wind turbine models for power system dynamic studies. Wind Eng 30(3):171-186

Ranjan SHARMA is a Power System Engineer with Siemens Wind Power A/S, Borupvej 16, Brander, 7330, Denmark. His work is mainly focusing on the wind turbine and wind power plant modeling and control, and VSC HVDC connection for offshore wind power.

Qiuwei WU is an Associate Professor with Centre for Electric Power and Energy, Department of Electrical Engineering, Technical University of Denmark, Kgs. Lyngby, DK-2800. His research interests are integration of wind power and electric vehicles into power systems, real time simulation of power systems, etc. 
Seung Tae CHA obtained the PhD from Centre for Electric Power and Energy, Department of Electrical Engineering, Technical University of Denmark in 2013 and is a senior power system engineer with Korean Power Corporation. His research interests are integration of renewable energy sources into power systems.

Kim H. JENSEN is a Power System Engineer with Siemens Wind Power A/S, Borupvej 16, Brander, 7330, Denmark. His work is mainly focusing on the wind turbine and wind power plant modeling and control.

Tonny W. RASMUSSEN is an Associate Professor with Centre for Electric Power and Energy, Department of Electrical Engineering,
Technical University of Denmark, Kgs. Lyngby, DK-2800. His research interests are power electronic components and their application for converter, and converters and their application for utility grid and wind turbine systems.

Jacob ØSTERGAARD received the M.Sc. in electrical engineering from the Technical University of Denmark (DTU), Lyngby, Denmark, in 1995. He was with Research Institute of Danish Electric Utilities for 10 years. Since 2005, he has been Professor and Head of Centre for Electric Technology, DTU. His research interests cover smart grids with focus on system integration of renewable energy and distributed energy resources, control architecture for future power system, and flexible demand. 